\title{
The Comparative Study on Occupational Mortality, 1980 between Japan and Great Britain
}

\author{
Sadanobu KAGAMIMORI ${ }^{*}$, Isamu MATSUBARA ${ }^{1}$, Shigeru SOKEJIMA ${ }^{1}$, Michikazu SEKINE ${ }^{1}$, \\ Tomoharu MATSUKURA ${ }^{1}$, Hideaki NAKAGAWA ${ }^{2}$ and Yuchi NARUSE ${ }^{1}$
}

\author{
${ }^{1}$ Department of Welfare promotion and Epidemiology, Faculty of Medicine, Toyama Medical and Pharmaceutical \\ University, 2630 Sugitani, Toyama City 930-01, Japan \\ ${ }^{2}$ Department of Public Health, Faculty of Medicine, Kanazawa Medical University, 1-1 Daigaku, Uchinada- \\ machi, Ishikawa 920-02, Japan
}

Received July 25, 1997 and accepted March 25, 1998

\begin{abstract}
Age-adjusted standardized mortality ratios (SMRs) and life tables in male occupational groups for all causes and major diseases such as malignant neoplasm of stomach and lung, cerebrovascular disease, ischemic heart disease, traffic accidents and suicide was compared between Japan and Great Britain. Except for traffic accidents and suicide, males in higher employment grades had lower SMRs which had also been found to be related to other social class indicators such as perinatal death rate, the frequency of work absence and current smoker's rate. Occupational differences in mortality rates for major diseases became smaller with advancing age in Great Britain but not necessarily in Japan. The present authors concluded that inequalities in socio-economical factors were more likely to be the primary factors for survival, and that selection such as occupation and occupation-related lifestyle might still be an important factor for the inequalities. These inequalities were more obvious in Japan, where a life expectancy was, however, best in the world.
\end{abstract}

Key words: Occupational mortality, Standardized mortality ratio SMR, Survival rate, Socio-economical factors, Japan and Great Britain

\section{Introduction}

Socio-economical factors played an important role for incidence, prevalence and mortality of many diseases. Among socio-economical factors, the occupation caused inequality in chance of survival. Since Japan and Great Britain use a similar classification of occupations in mortality statistics, the present authors have already compared occupational mortality rates around 1970 between the two countries ${ }^{1-3}$. For stomach cancer, lung cancer, cerebrovascular disease and ischemic heart disease, big differences in mortality rates were found between the two countries. These findings resulted from differences in life styles in each country, and even the

*To whom correspondence should be addressed. highest occupational survival rate in one country was still lower than the lowest one in the other country for these diseases. In spite of these differences, the previous studies indicated that major causes of death had parallel occupational gradients to the social ranking in both countries.

By advance of technology, it could be considered that work characteristcs of occupations changed and that an inequality of survival among occupation changed. Data on occupational mortality around 1980 published in the two countries introduced us an opportunity to compare and to investigate correlation between social gradients and mortality rates.

\section{Materials and Methods}

Occupational data for the male population was available from the Report of the Japanese Census 1980, and from a 
sample of $10 \%$ of all males in Great Britain in 1981, and population aged 20 to 54 was 28.2 million and 11.8 million, respectively. In Japan, occupations were grouped in a similar way as in Great Britain. In the present study, occupations were classified into professional technical workers and artists (P: $7.7 \%$ in Japan, $17.1 \%$ in Great Britain), administrators and managers (A: $7.0 \%, 12.1 \%)$, clerical workers (C: $12.1 \%$, $6.7 \%$ ), sales workers (Sa: 14.3\%, 3.7\%), farmers, foresters and fishermen ( $\mathrm{F}: 9.2 \%, 1.9 \%)$, miners and quarrymen (Mi: $0.2 \%, 6.1 \%$ ), transport and communications workers ( $\mathrm{T}$ : $6.6 \%, 10.4 \%$ ), security and protective service workers (Sp: $2.1 \%, 3.1 \%$ ), service, sport and recreation workers (Se: $3.9 \%$, $3.5 \%)$ and other workers (O: $35.9 \%, 29.9 \%)$. The last grouping was necessary because of difference of sub-group classification between the two countries. It consisted of production process and engineering workers, laborers and other miscellaneous minor occupations. Occupation Mi in Japan was excluded from the analysis because of a small population size and its particularly higher mortality rates.

Age-specific occupational mortality rates were available in Japan from the Report of Occupational Mortality in Japan $1980^{4}$, and in Great Britain from the Decennial Supplement on Occupational Mortality $1979-80$ and $1982-83^{5)}$. With regard to occupational classification for non-workers on death, there is a different way between the two countries. In Japan occupations in the death certificates are classified into no work if they have already retired. In Great Britain, however, last full-time occupation are put in for these cases. For the calculation of standardized mortality ratios (SMRs), expected number of death was obtained as follows; personyear at risk by age in each occupation was multiplied by age specific mortality rate for all working males except for Occupation Mi in Japan during given periods in each country.

Deaths were classified by cause according to the International Classification of Disease (ICD) 9th Revision ${ }^{6}$ stomach cancer (ICD 151), lung cancer (ICD 162), cerebrovascular disease (ICD 430-438), ischemic heart disease (ICD 410-414), traffic accidents (ICD E810-E825) and suicide and self-inflicted injury (Suicide, ICD E950-E959).

In order to reduce population size dependent bias, based on the order of SMRs for all causes by occupation in each country (as shown in Fig. 1), occupational categories were combined to compose four groups of larger population size in order to compute occupation group-specific life tables. In Japan, the Group I consisted of Occupation P and A, the Group II of Occupation O, the Group III of Occupation Sp, $\mathrm{C}$ and $\mathrm{T}$, and the Group IV of Occupation $\mathrm{Sa}$, Se and $\mathrm{F}$. In Great Britain, the Group I (Occupation P and A), the Group
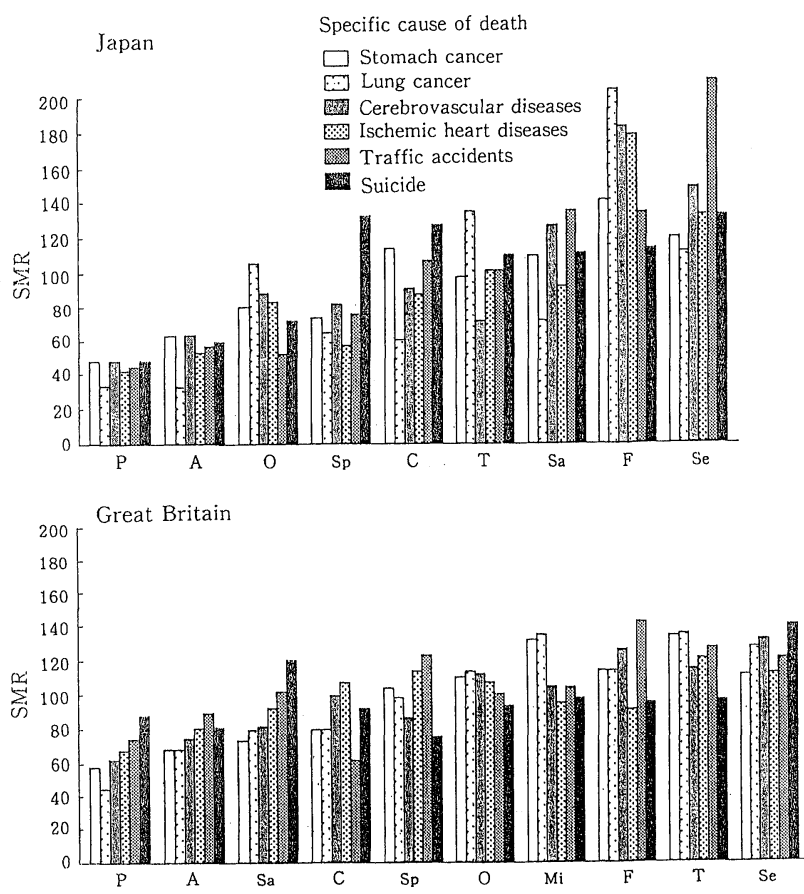

Fig. 1. Age-adjusted SMRs for male working population aged 2054 years by occupation in Japan and Great Britain Occupation P: Professional Technical workers and artists, A: Administrators and managers, C: Clerical workers, Sa: Sales Workers, F: Farmers, foresters and fishermen, Mi: Miners and quarry men, T: Transport and communication workers, Sp: Security and protective Service workers, Se: Service, sport and recreation workers, O: Other workers, mainly craftsmen, production process workers and laborers.

II (Occupation Sa, Sp and C), the Group III (Occupation O) and the Group IV (Occupation $\mathrm{Mi}, \mathrm{F}, \mathrm{T}$ and $\mathrm{Se}$ ) were correspondent to those in Japan.

For comparison of mortality rates at each decade of age among occupational groups, mortality ratios were expressed as percentages of the mortality rate to occupational group I. Lung cancer and ischemic heart disease in Japan and stomach cancer and cerebrovascular disease in Great Britain were excluded because of small number of deaths.

Smoking status by occupation in 1982 was available from Decennial Supplement on Occupational Mortality 1979-80, 1982-83 in Great Britain ${ }^{5)}$. Perinatal death rates and the frequency of persons who had no absence owing to illness on working days in 1980 by occupation were available in $\mathrm{Japan}^{7)}$. These indices were also analysed in order to investigate the correlation with SMRs by occupation. For the latter indicator, however, the occupation consisted of five groups (Occupation $\mathrm{P}, \mathrm{A}$ and $\mathrm{C}$, Occupation $\mathrm{Sa}$, Occupation F, Occupation T. Mi and O, and Occupation Sp 
Table 1. Rank correlation coefficients between SMRs of major diseases by occupation

\begin{tabular}{llcccccc}
\hline & 1 & 2 & 3 & 4 & 5 & 6 & Perinatal Death \\
\hline 1. Stomach Cancer & & $0.91^{* *}$ & $0.88^{* *}$ & $0.82^{* *}$ & $0.71^{*}$ & $0.75^{*}$ & $0.78^{*}$ \\
2. Lung Cancer & $0.98^{* *}$ & & $0.81^{* *}$ & $0.89 * *$ & 0.48 & 0.54 & $0.86^{* *}$ \\
3. Cerebrovascular Disease & $0.79^{*}$ & $0.85^{* *}$ & & $0.92^{* *}$ & $0.69 *$ & $0.72^{*}$ & $0.71^{*}$ \\
4. Ischemic Heart Disease & $0.65^{*}$ & $0.67^{*}$ & 0.62 & & 0.48 & 0.52 & $0.88^{* *}$ \\
5. Traffic Accidents & $0.72^{*}$ & $0.74^{*}$ & $0.78^{*}$ & 0.47 & & $0.73 *$ & 0.57 \\
6. Suicide & 0.28 & 0.39 & $0.67^{*}$ & 0.04 & $0.67 *$ & & 0.53 \\
$\quad$ Smoking (\%) 1982 & $0.80^{* *}$ & $0.82^{* *}$ & $0.76^{*}$ & $0.74^{*}$ & 0.58 & 0.47 & \\
\hline
\end{tabular}

Upper-right: Japan, Lower-left: Great Britain, *: p<0.05, **: p<0.01.

and Se). Therefore, the SMRs was recalculated according to this classification.

\section{Results}

Age-adjusted SMRs by occupation and cause of death in Japan and Great Britain were illustrated in Fig. 1. Occupation groups were shown according to the order of SMR for all causes of death in each country. The SMR of all causes in each occupation in Japan increased in the following order: Occupation P, A, O, Sp, C, T, Sa, F and Se. On the other hand, the order was Occupation $\mathrm{P}, \mathrm{A}, \mathrm{Sa}, \mathrm{C}, \mathrm{Sp}, \mathrm{O}, \mathrm{Mi}, \mathrm{F}, \mathrm{T}$ and $\mathrm{Se}$ in Great Britain. In both countries, Occupation $\mathrm{P}$ had the lowest SMR, followed by Occupation A. Occupation Se had the highest SMR in both countries. There was a big difference in the order of the SMR of Occupation Sa between the two countries. It was the third highest in Japan but the third lowest in Great Britain.

In Japan, a proportional mortality ratios to all causes was 9.2\% for stomach cancer, $2.7 \%$ for lung cancer, $13.5 \%$ for cerebrovascular disease, $4.8 \%$ for ischemic heart disease, $7.1 \%$ for traffic accidents, and $11.5 \%$ for suicide in 1980 . The total of these proportions summed up to $48.8 \%$. In Great Britain, the proportional mortality ratio was $1.8 \%$, $7.3 \%, 4.9 \%, 32.9 \%, 6.6 \%$ and $5.6 \%$ in $1979-80$ and 1982 83 , respectively. The total of these proportions summed to $59.1 \%$. The stomach was relatively dominant in Japan while the lung in Great Britain for the site of malignant neoplasm, and the cerebrum was relatively dominant in Japan while the heart in Great Britain for the site of vascular pathology.

In both countries, the SMRs in each specific cause of death adopted in this study presented a similar gradient by occupation. In order to clarify these trends of SMRs, rank correlation coefficients were calculated between specific causes of death in each countries (Table 1). In Japan, SMRs of stomach cancer and cerebrovascular disease showed statistically significant positive correlation with the other five causes.

With regard to perinatal death rate in Japan, correlation coefficients in relation to the SMRs were shown in Table 1. SMRs for stomach cancer, cerebrovascular disease and ischemic heart disease correlated significantly with perinatal death rates. The scattered diagram between the perinatal death rate and SMR for all causes were drawn in Fig. 2 (a). In addition, among Japanese males, the percentage of persons who had no work absence owing to illness correlated positively with the SMRs for all causes $(r=0.98, p<0.01$ : Fig. 2 (b)), stomach cancer $(r=0.55$, n.s.), cerebrovascular disease $(r=0.34$, n.s. $)$, traffic accidents $(r=0.18$, n.s. $)$ and suicide $(r=0.26, n . s$.) of death by occupation. In Great Britain, the correlation coefficient of smoking habit in relation to SMR for all causes was highest $(r=0.85, p<0.01)$, and the second highest was that in relation to SMR for lung cancer $(r=0.80, p<0.01)$ as shown in Table 1 . The scattered diagram between current smoker's rate and SMR for lung cancer by occupation was drawn in Fig. 2 (c).

For comparison of mortality rates at each decade of age among four occupational groups (I to IV), the mortality ratios (Occupational group $\mathrm{I}=100 \%$ at each decade of age) were drawn in Fig. 3. In Japan, the mortality ratios of all causes for groups II-IV had trends to increase with advancing age and were higher at the older ages of 40-54 years. For stomach cancer and cerebrovascular disease, mortality ratios were increasing with advancing age for the aged over 30 and were higher at older ages except for stomach cancer of occupational group II. In Great Britain, the mortality ratios for all causes were stable and above $100 \%$ at each decade of age for all three occupational groups. For lung cancer, the mortality ratios were higher than $100 \%$ at over 30 years of age, but decreased a little in the age of 50's. The mortality ratios of ischemic heart disease and traffic accidents were higher than $100 \%$ at each decade of age, and generally tended to decrease 
(a) Perinatal death rate and SMR of all causes by occupation in Japan

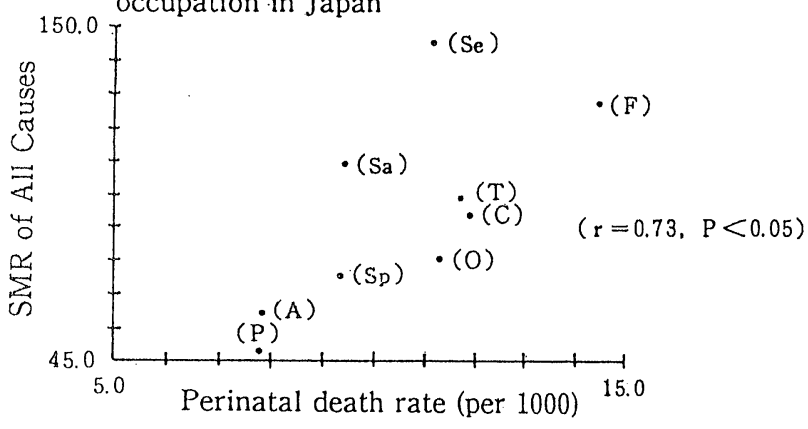

(b) Percentage without work absence and SMR of all causes by occupation in Japan

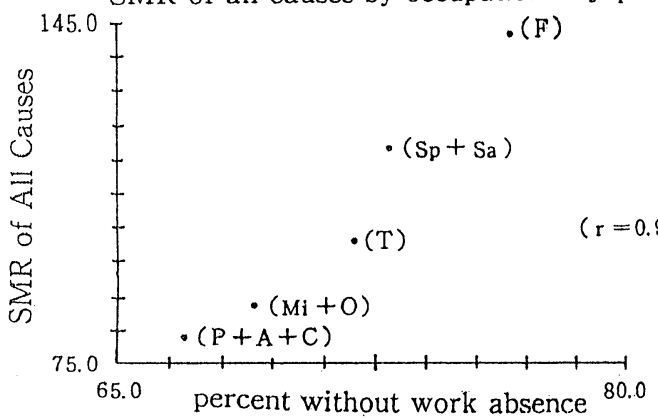

(c) Smoking habit and SMR of lung cancer by occupation in Great Britain

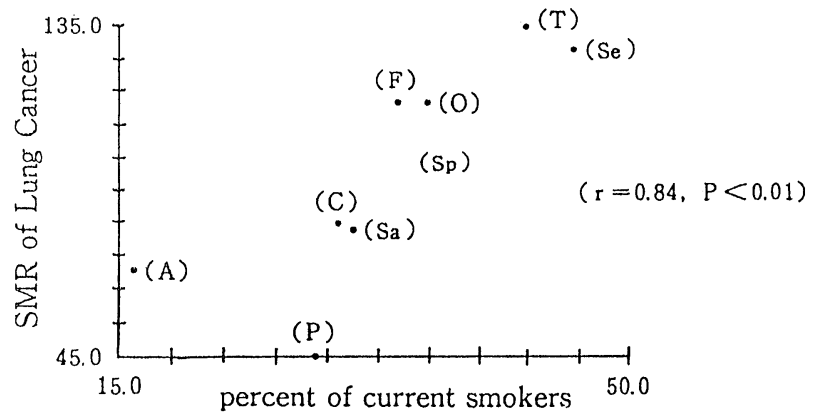

Fig. 2. The scattered diagram between selected indicators and SMRs by occupation in Japan and Great Britain

with advancing age. For the mortality ratios of suicide, at age 50's, the difference among occupational groups disappeared and their values were almost focussed into the average. When comparing the mortality ratios between the two countries, occupational differences became smaller with advancing age for ischemic heart disease, suicide and all causes in Great Britain but not in Japan.

\section{Discussion}

First of all the different ways in definition of last
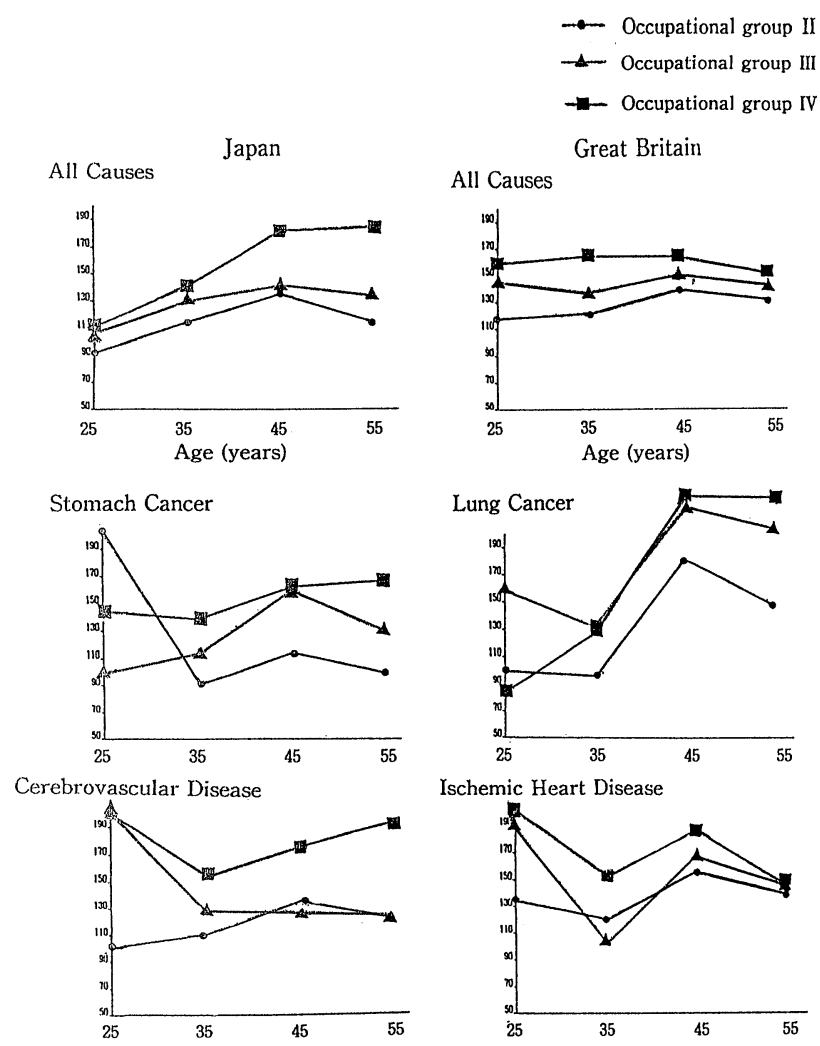

Ischemic Heart Disease
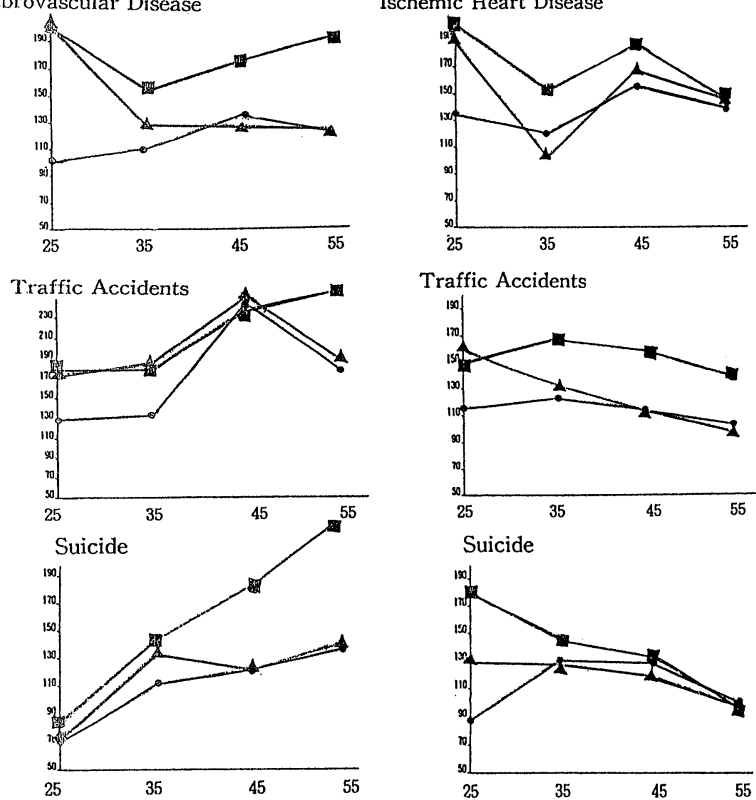

Traffic Accidents

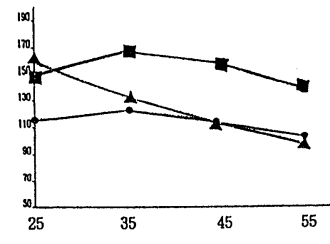

Suicide

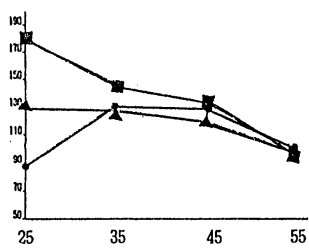

Fig. 3. Age specific mortality ratios of occupational group II, III and IV as percentages of occupational group I $(=100 \%)$

occupations between Japan and Great Britain could cause certain biases for inequalities in mortality of occupational groups. For instance, in Japan healthy worker effect could reduce occupational mortality differences because of the tendency for workers with reduced health status either to retire or to become unemployed. For Great Britain due to either retirement or unemployment the living ways could be different from those of their previous occupational groups and it tends to increase their mortality.

Occupational mortality differences are partially explained 
by the social selection. In fact, Stern argues social mobility that better health leads upward, and poor health downward ${ }^{8}$. As Hart points out, however, major explanation for occupational mortality differences should be sought from socio-economical factors such as wealth and income, housing, educational and employment opportunity and from behavioral characteristic ${ }^{9}$.

There were many studies that demonstrated child mortality to be related to socio-economical factors ${ }^{10,11}$. Comparing age-adjusted SMRs of some major diseases by adult male occupational group with stillbirth rates of their groups in the previous study, the present authors have already confirmed the close correlation between these occupational gradients in Japan and England and Wales ${ }^{1)}$. Since perinatal death rate by occupation was available in Japan, it was used for a socio-economical ranking in the present study. Although SMRs of traffic accidents which were rather accidental, and of suicide showed no significantly positive correlation with perinatal death rates by occupation, major causes of death such as stomach and lung cancer, cerebrovascular disease and ischemic heart disease showed similar results as previously confirmed by us. Since this correlation might appear circular, it could be said that socio-economical factors determined each individual's life chances to a very great extent before or just after they were born.

In order to look at behavioral factors, work absence owing to illness was adopted and compared with the gradients of occupational SMRs in Japan. Lower occupational groups showed higher percent of no absence persons than higher occupational groups in this study, though, it was reported that the percentage of persons who had no absence owing to illness negatively correlated to disease prevalence in populations ${ }^{12}$. Furthermore, the higher groups more frequently used health services ${ }^{13)}$. These implied more healthconscious behavior in higher occupational groups, thus increasing the gap in survival between occupational groups.

Smoking habit has been demonstrated to attribute to occupational inequalities in mortality ${ }^{14)}$. In the last 20 years or so, there was a marked reduction in a proportion of current smokers, particularly in the higher occupational groups. As a result of these changes in Great Britain, an apparent relationship between a gradient for smoking and that for mortality from smoking associated diseases such as lung cancer and ischemic heart disease was observed. In addition, the close correlations of smoking habits with mortality from all causes, stomach cancer and cerebrovascular disease were confirmed. These results suggested that the smoking habits of adult also represented socio-economical circumstances in Great Britain as previously found ${ }^{1}$. At present, although such data on smoking were not available in Japan, the same relationship between a gradient for smoking and that for mortality from smoking associated diseases might exist.

Hart has already pointed out that social class gradients were steeper at younger ages, particularly in accidental causes which were very strongly class-related ${ }^{9)}$. Furthermore, prospective studies of people exposed to particular occupational hazards also indicated that direct effects of occupation had greater impact on SMRs at younger than at older age ${ }^{15}$. In the present study, the same or at least no contradictory tendency was observed for all and major causes of death such as lung cancer, ischemic heart disease, traffic accidents and suicide in Great Britain. The differences in mortality rates among occupational groups, however, widened at older ages for all and leading causes such as stomach cancer and cerebrovascular disease in Japan.

McCarthy et al. ${ }^{16)}$ emphasized the cumulative effects of socio-economical factors on deaths; social class mortality differentials at older ages had to be attributed to their socioeconomical variables, lifestyles and circumstances in the period leading up to their deaths. The large occupational differences in survival rates in Japan might be explained by this reason.

To explain occupational mortality gradients mentioned above, another reason had to be considered; the healthier and fitter members of society gravitated to the higher occupational hierarchy, while the less fit and therefore the less successful sank to the bottom ${ }^{9}$. Fox et al., however, observed in the longitudinal study that selective health related mobility between social classes did not contribute to differentials in mortality in Great Britain ${ }^{17}$.

The observation of social class differences for mortality from diabetes mellitus was shown in Table 2. In 1921 when insulin was just confirmed to be a causative substance for diabetes mellitus, the higher social classes had higher mortality compared with lower social classes. The gradient, however, gradually shifted to the opposite direction. Higher classes would have easier access to effective medical control inclusive of pharmaceutical, dietary and physical therapies. In addition, preventive activities against diabetes mellitus may have been introduced more rapidly and more widely among higher social classes. The comparison of mortality from diabetes mellitus between 1921 and 1971 indicated that reduction in the mortality among higher classes induced the gradient shift to the opposite direction.

Mortality from different causes, nowadays, showed identical social class gradients, i.e., lower mortality in higher classes. It was important that mortality gradient related to 
Table 2. Mortality from Diabetes Mellitus in Great Britain: 1921 and 1971 (per 100,000)

\begin{tabular}{clllcccr}
\hline Social class & year & $15-24^{\mathrm{A}}$ & $25-34$ & $35-44$ & $45-54$ & $55-64$ & SMR \\
\hline \multirow{2}{*}{ I } & 1921 & 4 & 6 & 5 & 19 & 47 & 130 \\
& 1971 & 0.3 & 0.3 & 2 & 3 & 11 & 84 \\
II & 1921 & 4 & 7 & 8 & 19 & 55 & 132 \\
& 1971 & - & 0.3 & 2 & 4 & 12 & 93 \\
III & 1921 & 4 & 5 & 7 & 11 & 30 & 93 \\
& $1971^{\mathrm{B}}$ & 0.3 & 0.7 & 2 & 4 & 13 & 103 \\
IV & 1921 & 4 & 5 & 7 & 9 & 21 & 76 \\
& 1971 & 0.5 & 2 & 2 & 4 & 12 & 111 \\
V & 1921 & 4 & 5 & 5 & 11 & 14 & 66 \\
& 1971 & 0.7 & 1 & 5 & 5 & 14 & 128 \\
\hline
\end{tabular}

${ }^{\mathrm{A}} 16-24$ in 1921, ${ }^{\mathrm{B}} \mathrm{III} \mathrm{N}$ and III M are combined. RESOUCES: "Decennial Supplement (1921, Volume II)", “Occupational Mortality (1970-1972)”.

socio-economical factors was observed in the developed countries which had substantial medical services. Furthermore, improvements in medical science and health promotion seemed to accelerate this tendency. Actually, there was a decline in mortality from all causes in these countries, but these improvements were not experienced equally across the population.

Now the World Health Organization's strategy for 'Health for All' is taking shape with the theme of 'equally in health', as one of its major principles. Findings of the present study carried out in developed countries indicate initiatives for the wider strategy on the WHO agenda in developing countries.

\section{References}

1. Kagamimori S, Iibuchi Y, Fox J (1983) A comparison of socioeconomic differences in mortality between Japan and England Wales. Wld Hlth Statist 36, 119-28.

2. Kagamimori S (1981) Occupational life tables for cerebrovascular disease and ischemic heart disease in Japan compared with England and Wales. Jap Cir C J 45, 195-201.

3. Naruse $Y$, Kagamimori S, Watanabe M, Minowa M, Iibushi Y (1985) Mortality rates for farmers and fishermen in Japan compared with England and Wales. Social Sci Med. 21, 139-43.

4. Vital Statistics Division of Ministry of Health and Welfare (1984) Report of occupational mortality rates 1980. Health and Welfare Statistics Association, Tokyo (in Japanese).

5. Office of Population Censuses and Surveys (1986) Decennial supplement on occupational mortality 197980, 1982-83. Great Britain, HMSO, London.
6. World Health Organization (1975) International classification of diseases, 9th ed, WHO, Geneva.

7. Vital Statistics Division of Ministry of Health and Welfare Report of the National Health Survey 1980 (1981) Health and welfare statistics association, Tokyo (in Japanese).

8. Stern J (1983) Social mobility and the interpretation of social class mortality differentials. J Social Policy 12, 27-32.

9. Hart N (1986) Inequalities in health: The individual versus the environment. J R Statist Soc A 149, 228-35.

10. Illsley $R$ (1955) Social class selection and class differences in relation to stillbirths and infant deaths. Br Med J ii, 1520-6.

11. Leete R, Fox J (1977) Registrar General's social classes: Originals and uses. Population trends 8, 1-8.

12. Office of Population Censuses and Survey (1979) General Household Survey 1975. HMSO, London.

13. Todd JE (1973) Children's dental health in England and Wales 1973. HMSO, London.

14. Pearce NE, Davis PB, Smith AH, Foster FH (1985) Social class, ethnic group, and male mortality in New Zealand, 1974-8. J Epid Community Health 39, 9-15.

15. Case RA, Hosker ME, McDonald DB, Pearson JT (1954) Tumours of urinary bladder in workman engaged in the manufacture and use of certain dyestuff intermediates in the British chemical industry. $\mathrm{Br} \mathrm{J}$ Industr Med 11, 75-83.

16. McCarthy P, Byrne D, Harrisson S, Keithley J (1985) Respiratory conditions: effect of housing and other factors. J Epid Community Health 39, 15-22.

17. Fox AJ, Goldblatt PO, Jones DR (1985) Social class mortality differentials: artifact, selection or life circumstances? J Epid Community Health 39, 1-8. 